\title{
Meta-analysis of side effects of statins shows need for trial transparency
}

\author{
Ben Goldacre Wellcome research fellow in epidemiology
}

London School of Hygiene and Tropical Medicine, London WC1E 7HT, UK

As Wise reported, ${ }^{1}$ our meta-analysis looked at side effects in randomised trials of statins and found that many, such as muscle aches, were reported to an equal degree by participants taking a placebo. Those side effects may therefore be partly non-pharmacological, and due to negative expectations, or the "nocebo" effect, as has been shown in research on other drugs. ${ }^{2-4}$ For treatments where sufficiently large numbers of participants have been randomised, trials can potentially give more accurate information than observational studies on side effects.

Unfortunately, although our methods were sound, the reliability of our findings is probably undermined by the poor reporting of side effects in clinical trials reports in academic journals, as discussed in our paper. Of particular interest is a study by IQWiG, the German government's cost effectiveness agency, which was published after our study was conducted. It found on average that complete information was given for $87 \%$ of adverse event outcomes in the clinical study report (the standard lengthy regulatory document for industry trials), but for only $26 \%$ of adverse event outcomes in the academic journal publication. $^{5}$

This is one more reason why the AllTrials.net campaign asks for all trials to be registered, with their full methods and results reported, including the clinical study report, if one has been created. We cannot help patients make informed decisions about the risks and benefits of treatments until this information is routinely shared with doctors, researchers, and patients. ${ }^{67}$

Competing interests: I am a co-author on the paper in question, and co-founder of the AllTrials.net campaign for transparency in clinical trials.

Wise J. Statins may have fewer side effects than is claimed, meta-analysis finds. BMJ 2014;348:g2151. (14 March.)

2 Amanzio M, Corazzini LL, Vase L, Benedetti F. A systematic review of adverse events in placebo groups of anti-migraine clinical trials. Pain 2009;146:261-9.

3 Liccardi G, Senna G, Russo M, Bonadonna P, Crivellaro M, Dama A, et al. Evaluation of the nocebo effect during oral challenge in patients with adverse drug reactions. $J$ Investig Allergol Clin Immunol 2004;14:104-7.

4 Myers MG, Cairns JA, Singer J. The consent form as a possible cause of side effects. Clin Pharmacol Ther 1987:42:250-3.

5 Wieseler B, Wolfram N, McGauran N, Kerekes MF, Vervölgyi V, Kohlepp P, et al. Completeness of reporting of patient-relevant clinical trial outcomes: comparison of unpublished clinical study reports with publicly available data. PLOS Med 2013;10:e1001526

6 Goldacre B. Statins have no side effects? This is what our study really found ... Guardian 2014. www.theguardian.com/science/blog/2014/mar/14/statins-side-effects-study-placeboben-goldacre.

7 Goldacre B. Statins have no side effects? What our study really found, its fixable flaws, and why trials transparency matters (again). Bad Science 2014. www.badscience.net/ 2014/03/statins-have-no-side-effects-what-our-study-really-found-its-fixable-flaws-andwhy-trials-transparency-matters-again/.

Cite this as: BMJ 2014;348:g2940

๑) BMJ Publishing Group Ltd 2014 